\title{
Real-scale investigation of the kinematic response of a rockfall protection embankment
}

\author{
S. Lambert ${ }^{1}$, A. Heymann ${ }^{1,2,3}$, P. Gotteland ${ }^{2}$, and F. Nicot $^{1}$ \\ ${ }^{1}$ Irstea, UR ETGR, 2 rue de la papeterie, 38402 St-Martin d'Hères, France \\ 23SR, UJF-INPG-CNRS-UMR5521, DU Grenoble Universités, 38041, currently, FNTP, 3 rue de Berri - 75008 Paris, France \\ ${ }^{3}$ Razel Society, Groupe Fayat, 3 rue René Razel, Christ de Saclay, 91892 Orsay Cedex, France \\ Correspondence to: S. Lambert (stephane.lambert@irstea.fr)
}

Received: 5 December 2013 - Published in Nat. Hazards Earth Syst. Sci. Discuss.: 21 January 2014

Revised: 21 March 2014 - Accepted: 14 April 2014 - Published: 23 May 2014

\begin{abstract}
This paper addresses the response of rockfall protection embankments when exposed to a rock impact. For this purpose, real-scale impact experiments were conducted with impact energies ranging from 200 to $2200 \mathrm{~kJ}$. The structure was composed of a $4 \mathrm{~m}$ high cellular wall leaned against a levee. The wall was a double-layer sandwich made from gabion cages filled with either stones or a sand-schreddedtyre mixture. For the first time, sensors were placed in different locations within the structure to measure real-time accelerations and displacements. The test conditions, measurement methods and results are presented in detail. The structure's response is discussed in a descriptive and phenomenological approach and compared with previous real-scale experiments on other types of embankments.
\end{abstract}

\section{Introduction}

Land constraints due to increasing urbanisation and economic growth of mountainous areas have motivated the development of different types of protection structures against natural hazards such as snow avalanches, rockfall and debris flows. Among these structures, embankments aim at protecting areas exposed to frequent occurrence and high-energy rockfall. Classically, these structures consist of reinforced earth dams, combined with a ditch for containing the intercepted blocks (Peila, 2011; Lambert and Bourrier, 2013). These structures exhibit a quasi-vertical upslope face to inhibit rock blocks from ramping over the barrier. The economic considerations in natural hazard management warrant significant research to improve the efficiency of these struc- tures in terms of both their ability to withstand the impact and their efficiency in arresting blocks (Lambert et al., 2013).

Many studies have been conducted with the aim of investigating the mechanical response of embankments for optimisation purposes (Peila, 2011; Lambert and Bourrier, 2013). In particular, real-scale experiments on embankments with impact energies higher than $1000 \mathrm{~kJ}$ have been conducted by different authors (Burroughs et al., 1993; Hearn et al., 1995, 1996; Yoshida, 1999; Peila et al., 2000, 2007; Maegawa et al., 2011). Impact experiments on real-scale structures have also investigated lower-energy rockfall (Aminata et al., 2008; Sung et al., 2008). In parallel, the cost of such experiments has motivated small-scale experiments in view of parametric studies (Blovsky, 2002; Hofmann et al., 2013). These studies have provided qualitative results of great value, but from a quantitative point of view questions concerning the suitability of these experiments to be upscaled may arise, in particular for $1 \mathrm{~g}$ tests.

The structures which have been the subject of real-scale experiments differ in shape, construction materials and size. For obvious cost reasons, the number of tests for each is rather limited. Extrapolation to other structures and to higher block kinetic energies may not be straightforward. Moreover, these studies provided only few experimental data with respect to the response of the structure during impact. Indeed, apart from data related to the block trajectory, measurements mainly concerned the embankment surficial deformation after impact.

This paper focuses on the mechanical response during impact of composite protection embankments made of geocells. The use of a geocell envelop with a geo-material fill was 
first proposed by Yoshida (Yoshida, 1999) for building rockfall protection embankments. The main advantage of such composite structures compared to monolithic and rigid ones is that they allow the impact energy to be transformed into deformation energy, mainly in the cellular protection wall, avoiding deformation within the rest of the structure (e.g. a ground-compacted levee). It is also possible to adapt the mechanical characteristics of the geocell depending on its position in the structure by changing the fill material. Finally, the cellular nature of the structure facilitates its repair in case of severe damage after impact.

In this study, the choice was made to use two materials exhibiting very different mechanical characteristics: a sandtyre shred mixture and crushed limestone. Gabion cages were used as geocell envelopes to provide a vertical front for the structure facing exposed to impact, referred to as the front facing.

To develop the use of such cellular rockfall protection embankments, an extensive research study was initiated, combining experiments with numerical modelling and following a multi-scale approach, from the constitutive material to the structure scale. For instance, experimental and numerical studies at the geocell scale (Bertrand et al., 2005; Lambert et al., 2009, 2011) and at the scale of an assembly of geocells were conducted (Bourrier et al., 2011; Dimnet el al., 2013; Heymann et al., 2010, 2011). The experimental facet of this study emphasized instrumentation monitoring, to investigate the structure's response and validate the derived numerical models. In addition to the re-use of end-of-life tyres, pollution to the environment and fire risk issues were also addressed (Hennebert et al., 2014).

This paper presents the real-scale impact experiments conducted in this study and addresses the impact response of the embankment under different impact energies. A detailed description of the tested structure and the instrumentation are provided. The test results are analysed focusing on the kinematic response of the structure subjected to a $210 \mathrm{~kJ}$ impact. Then the results from tests with impact energies up to $2200 \mathrm{~kJ}$ are presented. The discussion highlights the main features of the response of embankments to localised impact.

\section{Materials and methods}

\subsection{Impacted structures}

The tested structure consists of a two-layered cellular sandwich wall leaned against a ground-compacted levee (Fig. 1). The wall is $4 \mathrm{~m}$ high, $8 \mathrm{~m}$ long and $2 \mathrm{~m}$ thick. The geocells consist of gabion cages made up of a hexagonal wire mesh with an $80 \times 120 \mathrm{~mm}$ mesh, and a $2.7 \mathrm{~mm}$ diameter wire. Gabion cages are parallelepiped in shape, $3 \mathrm{~m}$ or $2 \mathrm{~m}$ long, subdivided into three or two $1 \mathrm{~m}^{3}$ cubic parts, respectively.

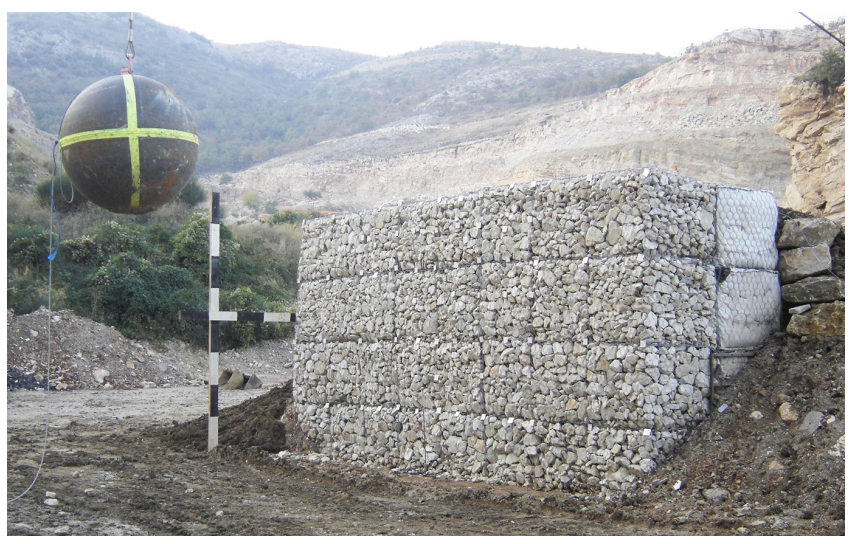

Figure 1. View of the tested embankment, showing the sandwich wall leaned against the levee and the hanging projectile.

Different granular fill materials are used according to the geocell location in the structure to form the layers of the wall. A crushed quarry limestone, $80-120 \mathrm{~mm}$ in grain size, is used for the front-facing geocells and a sand-shredded tyre mixture filled the kernel geocells. The sand size distribution ranges from 0 to $4 \mathrm{~mm}$. The sand-tyre mixture contains $30 \%$ by mass of tyre pieces with no particular shape with a size ranging from 20 to $150 \mathrm{~mm}$. The tyre pieces result from the shredding of recycled end-of-life tyres. This material was considered both for waste recycling purposes and to take advantage of its particular mechanical characteristics: this mixture constitutes a reinforced composite material and is expected to attenuate dynamic loadings (Zornberg et al., 2004; Lee and Roh, 2007; Gotteland et al., 2008). A non-woven needle-punched geotextile is used to maintain this fine fill material within the gabion cage.

As is done on actual worksites, the empty gabion cages are positioned at their final place and stapled together (five to eight clips per edge). Stone geocells (i.e. geocells filled with crushed limestone) are filled with $0.30 \mathrm{~m}$ thick layers of stones using a power shovel; the facing stones are arranged by hand. Sand and shredded tyres were mixed onsite before being poured into the geocell to form sand-tyre geocells (i.e. geocells filled with the sand-tyre mixture). Internal connecting wires are placed across both stone geocells and sandtyre geocells every $0.30 \mathrm{~m}$ during filling to prevent geocell deformation as a result of gravity loading. This is also intended to facilitate repair work in case of severe damage to the front facing due to a block impact. Uncertainty associated with the gabion cage volume makes accurate geocell unit mass measurement impossible. From previous experiments in this study, an approximate unit mass of $1400 \mathrm{~kg} \mathrm{~m}^{-3}$ and $1600 \mathrm{~kg} \mathrm{~m}^{-3}$ can be considered for sand-tyre geocells and stone geocells, respectively.

The levee was made using ground materials on site, compacted by $0.5 \mathrm{~m}$ thick layers with a vibrating-plate compactor, giving an average unit mass of $1970 \mathrm{~kg} \mathrm{~m}^{-3}$ (ranging 


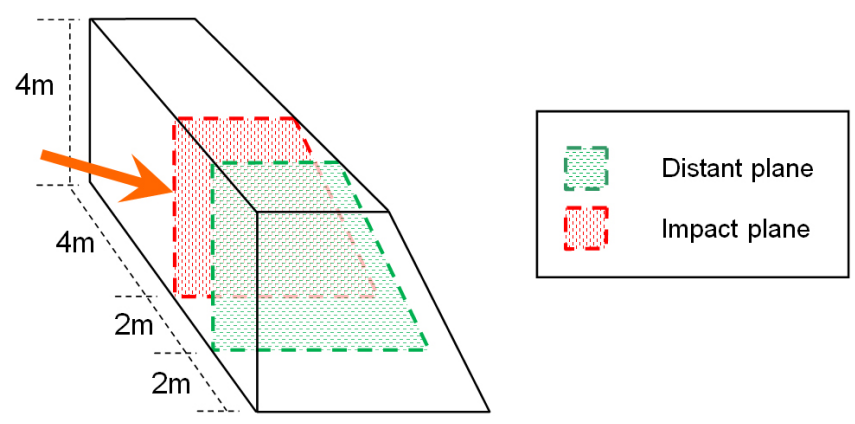

Figure 2. Sensors within the structure were placed in two vertical planes: in the impact direction and $2 \mathrm{~m}$ aside.

from 1850 to $2100 \mathrm{~kg} \mathrm{~m}^{-3}$ ). However, soil near the cellular wall was not compacted to avoid damaging the inclinometers in the levee (see Sect. 2.3).

\subsection{Experimental equipment}

The experiments were conducted in a limestone quarry in the French Alps. This site offers a $100 \mathrm{~m}$ long flat area at the toe of a $30 \mathrm{~m}$ high quasi-vertical cliff, for installing the conveying system and building the structure.

The conveying system is a cableway composed of a steel cable $50 \mathrm{~mm}$ in diameter anchored at the top of the cliff and beyond the structure location. The projectile is hung by a cable sling connected to a trolley placed on the cable. The trolley is then pulled up to the targeted position before being released. The trolley conveys the sphere downwards to the embankment, reproducing realistic impacts, that is (i) inclined with angles ranging from $18^{\circ}$ to $24^{\circ}$ with respect to the structure's front facing (ii) with a $28 \mathrm{~m} \mathrm{~s}^{-1}$ maximum impact velocity and (iii) at heights ranging from 1.75 to $2.10 \mathrm{~m}$ above the natural ground. These characteristics can be considered representative of mean natural event characteristics.

For safety reasons and because of possible interaction with equipment used for quarrying operations, it was not possible to use pyrotechnic release systems as is often the case when testing rockfall protection structures. The projectile remains suspended to the pulley throughout the test. Controlling the projectile trajectory before the impact and the impact location is the advantage of this technical solution.

The projectile consists of two half-spheres made of steel, $20 \mathrm{~mm}$ thick, welded along the median plane to form a $1.60 \mathrm{~m}$ diameter sphere. This sphere is filled with concrete giving the projectile a mass of $6500 \mathrm{~kg}$. Its unit mass is approximately $3030 \mathrm{~kg} \mathrm{~m}^{-3}$, which is considered satisfactorily close to the unit mass of rocks. An inside space is left so that accelerometers can be inserted at its mass centre. Even though the conic shape is more penetrative (Pichler et al., 2005), the spherical shape has been chosen because it facilitates interpretation of the results to overcome issues related to the shape of the surface in contact with the structure during the impact. Phe-

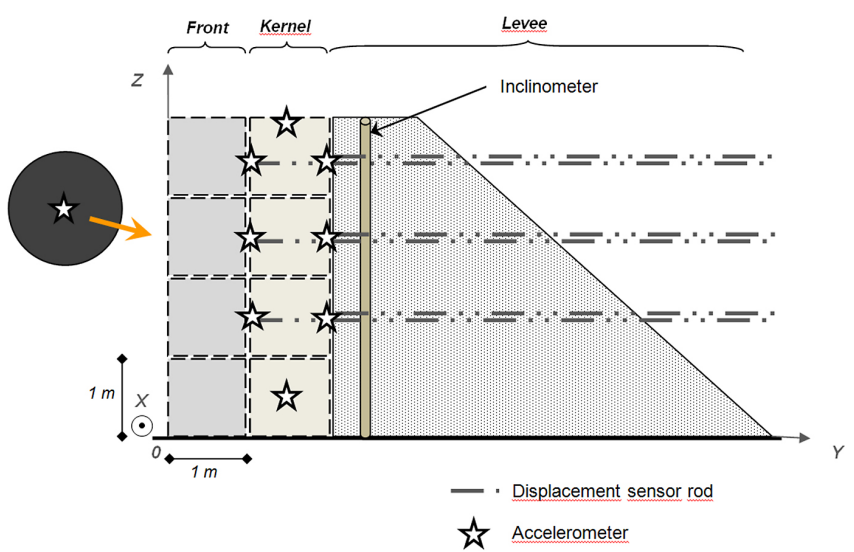

Figure 3. Cross section of the tested structure in the impact plane and measuring devices.

nomena that could result from the angular shape (punching or tearing of the wire mesh) are avoided.

\subsection{Instrumentation}

Different instrumentation was employed to measure the structure's response to impact. External measurements as well as internal measurements were taken, with the latter type concerning the projectile, the sandwich wall and the levee. The majority are real-time measurements taken during the impact.

The instrumentation design considered the following monitoring challenges of: (i) a structure partly built with coarse noncohesive granular material, (ii) the existence of discontinuities (gabion cages) and (iii) large and localised deformation during the impact. Since this context is rather aggressive to sensors and there was no guarantee that the sensors would perform satisfactorily, redundant measurements were taken using different techniques. This redundancy aims at increasing the chance of obtaining data while testing and validating the measurement devices in this particular context.

The structure is instrumented with the aim of evaluating (i) the displacements, (ii) the energy transfer and (iii) the damage to the structure. Stress measurements were not possible given the coarse nature of the fill materials. As shown in Fig. 2, the measurement devices were placed in two vertical planes normal to the front facing: the first in the impact direction and the second one $2 \mathrm{~m}$ distant, respectively referred to as the "impact plane" and the "distant plane" in the following. In the impact plane, displacements are assumed to occur in this plane for symmetry reasons only, contrary to the distant plane where normal-to-the-plane displacements are expected. The position of the sensors in the impact plane is depicted in Fig. 3.

Displacements within the embankment are measured using rod displacement sensors connected to six different points in the impact plane: three points at the front-kernel 


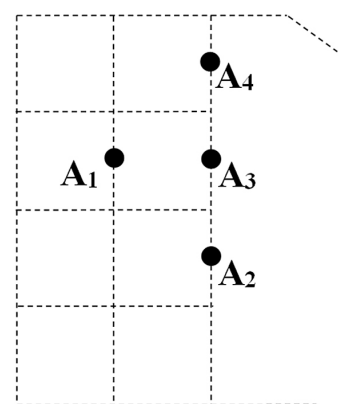

Impact plane

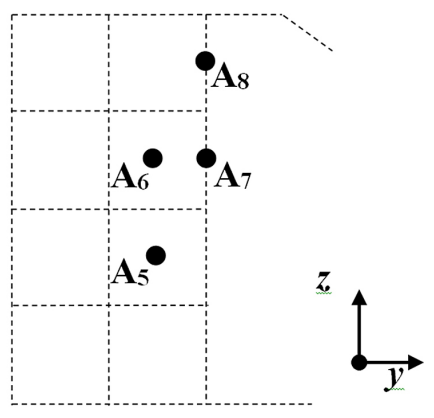

Distant plane
Figure 4. Accelerometers considered in this study.

interface and three at the kernel-levee interface, at three heights from the ground $(1.5,2.5$ and $3.5 \mathrm{~m})$. The six displacement sensors are supported by a rigid steel beam at the rear of the levee.

Accelerometers placed within and on the structure allow monitoring of the compression wave propagation and soil particle displacement. The piezo-resistive technology was preferred to other accelerometer technologies based on previous impact experiments involving smaller impact energies on a smaller structure (Haza-Rozier et al., 2010; Heymann et al., 2010). In the impact plane, eight different points within the structure are equipped: six accelerometers at the same locations as the displacement sensor extremities and two others in the middle of the kernel, 0.5 and $4 \mathrm{~m}$ above the ground. In the distant plane, accelerometers are positioned at five different points, in the middle of the kernel and at the kernellevee interface. Depending on the expected displacement of the point considered, acceleration is measured in one, two or three directions. A total of eleven acceleration measurements concern the impact plane and nine concern the distant plane. For this purpose, a uni-axial accelerometer (measuring range $\pm 200 \mathrm{~g}$, bandwidth $0-1.5 \mathrm{kHz}$ ) and a tri-axial accelerometer (measuring range $\pm 100 \mathrm{~g}$, bandwidth $0-1 \mathrm{kHz}$ ) are used. Accelerometers are placed on PVC supports and protected from impact by a cap. The supports are fixed to the gabion mesh. The locations of the accelerometers considered in this study are shown in Fig. 4. Data is referred to using the accelerometer number (nos. 1-4 and nos. 5-8 in the impact plane and distant plane, respectively) and the measurement direction with respect to the global system of axes shown in Fig. 4.

Displacements within the levee along the vertical axis are measured with an automatic inclinometer placed $0.5 \mathrm{~m}$ beyond the levee-kernel interface in the impact plane. Another inclinometer is located in the distant plane, at the same distance from the kernel-levee interface.

The experiments were filmed using a high-speed camera at a rate of 250 frames per second, which was used to determine the impact angle and projectile incident velocity, and to calculate the impact energy. Images during the impact were used to track the penetration of the projectile in the embankment

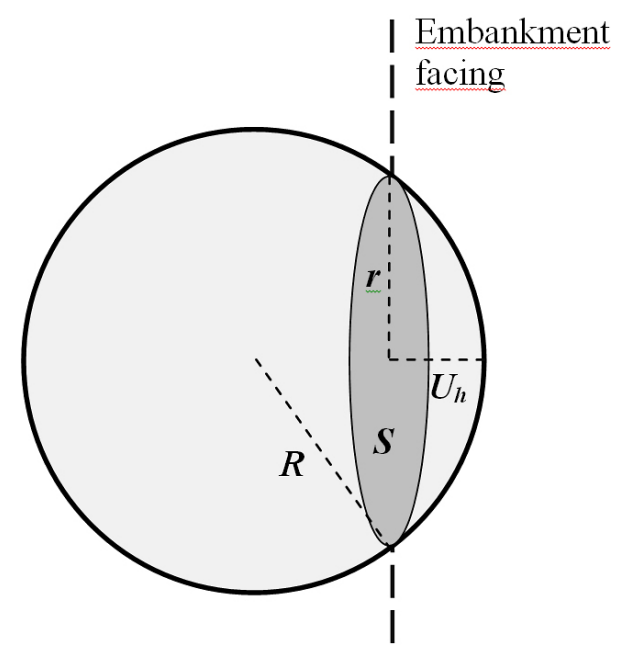

Figure 5. Definition of the contact surface between the projectile and the embankment.

but could not be used to compute its velocity and acceleration, because the frequency was too small to reproduce the rapid changes in acceleration satisfactorily.

A topographical survey was performed before and after each impact to monitor the external deformation of the structure, also giving the sensor's exact position during structure construction. Targets are fixed on the wire mesh of the front face, with spatial frequencies of 0.5 and $1 \mathrm{~m}$ in the vicinity and $2 \mathrm{~m}$ away from the impact area, respectively. Tomography was used for estimating changes in the levee's mechanical characteristics. Velocities of $P$ waves and $S$ waves are measured before and after each impact. The correlation function is calculated for each measuring point in the levee from the succesive seismic traces. The time-lag obtained from this correlation function gives the variation of seismic wave velocity resulting from the impact.

The projectile is equipped with a triaxial capacitive accelerometer $( \pm 200 \mathrm{~g})$ placed at its centre of mass. As the projectile was free to rotate, the orientation of the accelerometer axis with respect to the embankment facing varied from one test to the other.

The data logger, with a synchronous acquisition on 24 channels at a $10 \mathrm{kHz}$ frequency, records the data from all the accelerometers, in the projectile and in the cellular wall. The automatic inclinometer and the displacement sensors have their own data loggers.

\subsection{Data treatment and validation}

The start of impact is considered as the time reference for all the signals. All the collected signals are corrected from the offset and filtered. This is particularly important when accelerometers are placed in contact with the crushed limestone fill. Indeed, impact leads to stone displacement and 


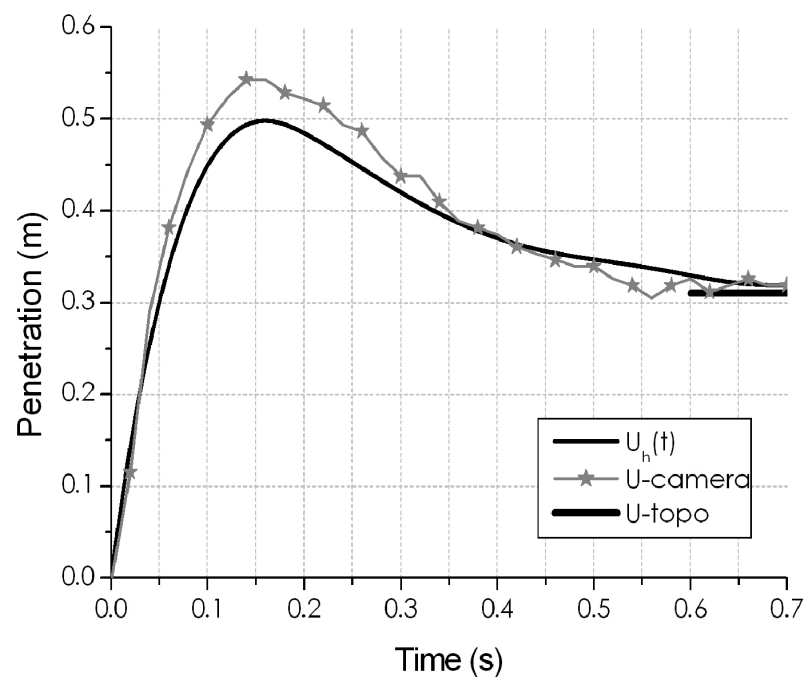

Figure 6. Comparison of the different penetration estimates $(210 \mathrm{~kJ}$ impact test).

crushing, resulting in very rapid force variations requiring signal smoothing (Lambert et al., 2009).

The projectile acceleration measurement is used to calculate the three components of the projectile velocity and displacement by successive time integrations. The kinetic energy of the projectile during the impact (KE) is calculated using the velocity norm. The displacement of the projectile from the impact beginning, $U(t)$, is calculated as the norm of the three components of the displacement. The penetration of the projectile in the embankment, normal to the vertical facing, is computed as the horizontal component of the projectile displacement:

$U_{\mathrm{h}}(t)=\cos \alpha \cdot U(t)$

with $\alpha$ the incident angle of the projectile.

The so-called impact force is derived from the projectile deceleration using Newton's second law. In order to compute a stress from this force, the surface considered is the interception between the embankment facing plane and the projectile (Fig. 5). The area of this surface is given by

$S(t)=\pi \cdot r^{2} \quad$ with $\quad r=\sqrt{2 \cdot R \cdot U_{\mathrm{h}}(t)-U_{\mathrm{h}}(t)^{2}}$,

with $R$ the radius of the projectile and $U_{\mathrm{h}}(t)$ its penetration in the embankment. This area represents the projection of the real facing-projectile contact surface on the surface normal to the penetration direction. It is thought to be the most relevant for computing a stress value based on the force acting on the projectile (i.e. the impact force).

The validity of the measurements and derived values was checked by comparing data from different sensor types.

The penetration derived from acceleration measurements fitted rather well with measurements from other methods (Fig. 6). A rather good agreement with displacement derived

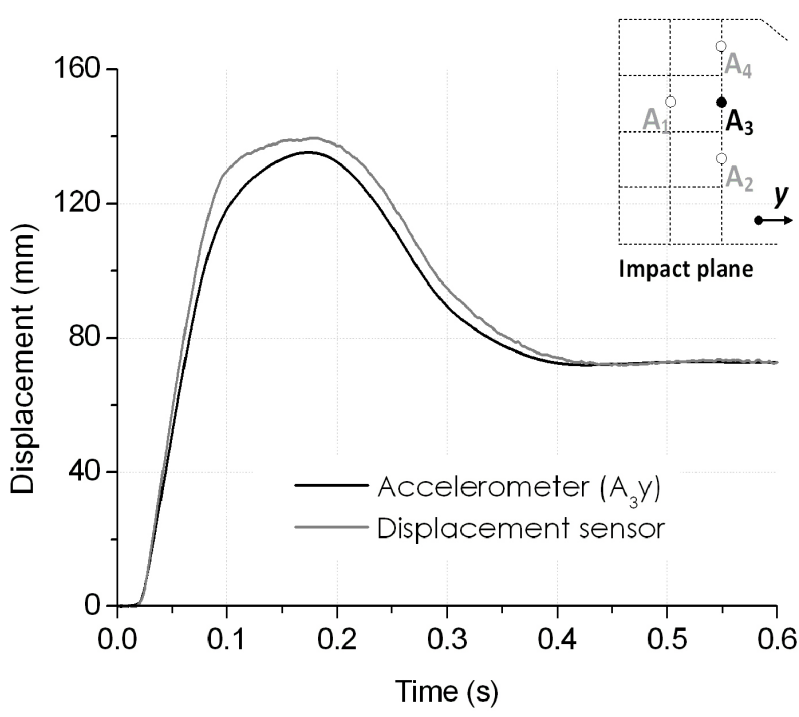

Figure 7. Comparison of the horizontal displacement $3.5 \mathrm{~m}$ from the ground at the kernel-levee interface, based on accelerometer and displacement sensor data $(2200 \mathrm{~kJ}$ impact test $)$.

Table 1. Impact conditions.

\begin{tabular}{lcccc}
\hline Test \# & $\begin{array}{c}\text { Kinetic } \\
\text { energy }(\mathrm{kJ})\end{array}$ & $\begin{array}{c}\text { Velocity } \\
\left(\mathrm{m} \mathrm{s}^{-1}\right)\end{array}$ & $\begin{array}{c}\text { Incident } \\
\text { angle }\left(^{\circ}\right)\end{array}$ & $\begin{array}{c}\text { Impact } \\
\text { height }(\mathrm{m})\end{array}$ \\
\hline 1 & 210 & 8 & 18 & 1.8 \\
2 & 1040 & 18 & 19 & 1.7 \\
3 & 540 & 13 & 26 & 2.1 \\
4 & 2200 & 26 & 24 & 2.1 \\
\hline
\end{tabular}

from the high-speed camera images was observed during impact $\left(U_{\mathrm{h}}(t)\right.$ vs. $U$-camera), as well as with the final indentation measured with topographical survey $\left(U_{\mathrm{h}}(t)\right.$ vs. $U$-topo). The accelerometer tended to slightly overestimate the acceleration, because penetration derived from this measurement was less than with the camera. The agreement concerning the maximum penetration values was considered good because the difference was about $10 \%$.

In a similar way, displacements within the embankment derived from accelerometer measurements were in rather good agreement with data from displacement sensors (e.g. Fig. 7). The difference was most often less than $10 \%$.

These comparisons validate the use of sensors in this context and the method for integrating acceleration to obtain the displacement with time.

\subsection{Experiments}

The experiments consisted in submitting the structure to successive impacts varying the projectile pre-impact velocity. Four levels of translational kinetic energy were targeted: 200, 500,1000 and $2000 \mathrm{~kJ}$. The real impact conditions are detailed in Table 1. 

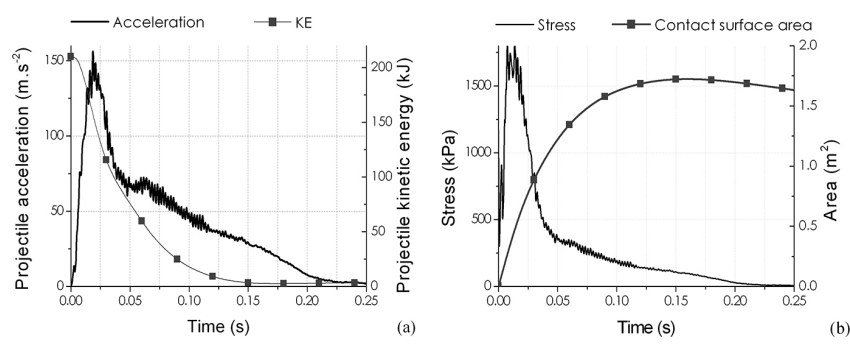

Figure 8. (a) Acceleration and kinetic energy of the projectile and (b) projectile/embankment contact surface and stress at the structure's front face during the $210 \mathrm{~kJ}$ impact test.

Structural damage was observed during the test series. It was limited for low-impact energies: the $210 \mathrm{~kJ}$ impact only led to a facing deformation, with minor stone breakage. With increasing energy, the deformation of the facing increased and progressively advanced to the rest of the structure. The $2200 \mathrm{~kJ}$ impact led to substantial facing damage with destroyed wire mesh and generalized stone crushing, but the structure remained stable after removing the projectile.

The structure facing was repaired before conducting tests 3 and 4 according to two techniques. When the impact resulted in severe damage to the front-facing geocells (test 2, with $1000 \mathrm{~kJ}$ impact), the geocells involved were removed and replaced with identical ones. Removing the front geocells was possible without any structural collapse risk due to the presence of internal connecting wires in the kernel geocells. In case of moderate damage, such as after test 3 , repair consisted in placing a wire mesh patch on the front facing, connecting it to the front wall geocells with wires and backfilling it with crushed quarry limestone. These repairs were assumed to restore the structure's ability to withstand the impact but obviously also slightly modified its characteristics.

In spite of the precautions taken for their installation, some sensors and sensor wires were damaged by the successive impacts. More precisely, large and non-uniform displacements that occurred in the structure led to tension in wires, resulting in excessive noise or absence of signal in some accelerometers. Shocks within the structure damaged some sensors mainly in contact with stones. This is particularly true for the last test, at the $2200 \mathrm{~kJ}$ impact energy, and to a lesser extent for test 3 . Due to a dysfunction of the main data logger, no data are available for test 2 .

\section{Analysis of experimental results}

The structure's response is investigated in detail based on the first experiment, with $210 \mathrm{~kJ}$ kinetic energy, given that all data were available. The analysis focuses on the accelerometer data. The results concerning the response of the structure to increasing impact energy are then presented.

\subsection{Structure response to the $210 \mathrm{~kJ}$ impact}

The impact of the projectile on the structure facing was characterised by a triangular and non-symmetrical projectile acceleration, with a peak value of $150 \mathrm{~m} \mathrm{~s}^{-2}$ (Fig. 8a). This maximum was reached $20 \mathrm{~ms}$ after the impact beginning and corresponds to an impact force of about $1000 \mathrm{kN}$. The total impact duration was about $200 \mathrm{~ms}$. The projectile kinetic energy rapidly decreased: it was less than half its initial value $40 \mathrm{~ms}$ after the impact beginning. Comparison with displacements depicted in Fig. 6 shows that the penetration at the acceleration peak time was $0.15 \mathrm{~m}$ and that the maximum penetration was reached long after this acceleration peak $(150 \mathrm{~ms}$ vs. $20 \mathrm{~ms}$ respectively).

The contact surface between the projectile and the structure facing increased with the projectile penetration (Fig. 8b) and the stress curve exhibited differences with the projectile acceleration curve: a steeper increase $(7 \mathrm{~ms})$, a wellmarked quasi plateau for almost $8 \mathrm{~ms}$ followed by a sharp decrease until $40 \mathrm{~ms}$. The maximum stress reached exceeded $1500 \mathrm{kPa}$, enough to generate stone crushing as locally observed after the test.

The structure's response to this loading is investigated in detail by using measurements from sensors within the embankment. Figure 9 shows acceleration, velocity and displacement along the $y$ axis direction of two points close to the impact axis direction, namely $A_{1}$ and $A_{3}$ located $2.5 \mathrm{~m}$ from the ground at the front-kernel and kernel-levee interfaces, respectively. Between the two acceleration peaks, a time lag of about $30 \mathrm{~ms}$ was observed together with an amplitude reduction by a factor of 8 .

Five different phases can be distinguished considering the three graphs plotted in Fig. 9. Phase I corresponds to a compression phase of the kernel. It lasts from 20 to $40 \mathrm{~ms}$ and follows the stress plateau observed in Fig. 8. During this phase, the first interface (i.e. $A_{1}$ ) experiences a rapid acceleration, contrary to the second interface (i.e. $A_{3}$ ). This difference in acceleration results in a difference in velocity and displacement (Fig. 9b, c). Phase II starts from the time the second interface begins moving $(40 \mathrm{~ms})$. From this time, the kernel is shifted progressively in the impact direction. Compression still develops due to the difference in velocity between the two interfaces. The maximal kernel thickness reduction is $120 \mathrm{~mm}$, reached at the end of this phase $(100 \mathrm{~ms})$. During the next phase (III, 100-145 ms), both velocities decrease but the kernel progressively expands due to the difference in interface velocity. This expansion lasts until the end of the impact. During phase IV (145-175 ms), the two interfaces move in opposite directions. Finally, in the last phase (V) both velocities are negative, revealing a global kernel displacement in the direction opposite the impact direction (Fig. 9c).

At the end of the impact, the kernel almost returns to its initial position with a thickness increased by about $25 \mathrm{~mm}$. By contrast, comparison of the projectile's penetration curve with the displacement curve of sensor $A_{1}$ reveals that the 

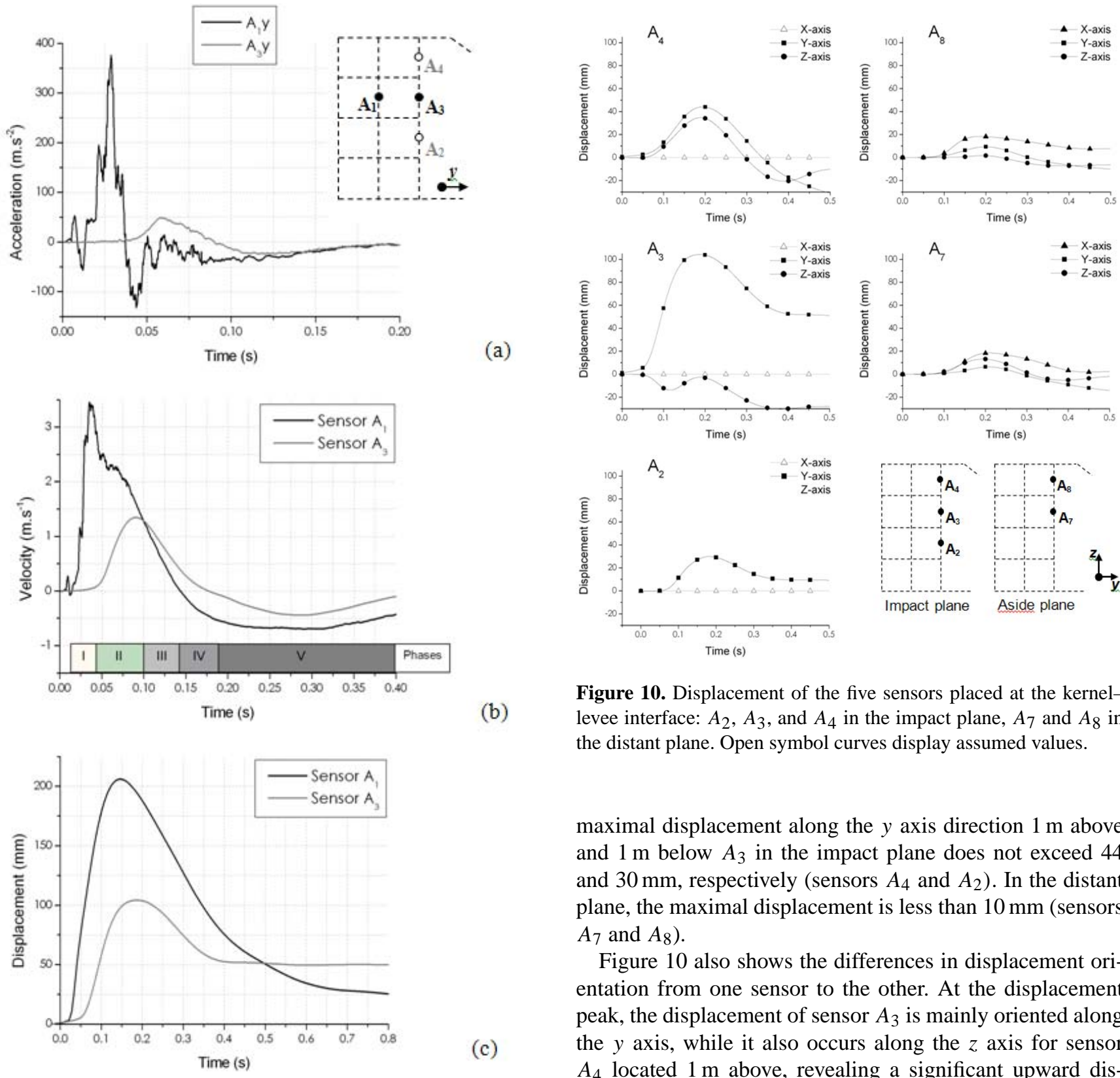
levee interface: $A_{2}, A_{3}$, and $A_{4}$ in the impact plane, $A_{7}$ and $A_{8}$ in the distant plane. Open symbol curves display assumed values.

maximal displacement along the $y$ axis direction $1 \mathrm{~m}$ above and $1 \mathrm{~m}$ below $A_{3}$ in the impact plane does not exceed 44 and $30 \mathrm{~mm}$, respectively (sensors $A_{4}$ and $A_{2}$ ). In the distant plane, the maximal displacement is less than $10 \mathrm{~mm}$ (sensors $A_{7}$ and $\left.A_{8}\right)$.

Figure 10 also shows the differences in displacement orientation from one sensor to the other. At the displacement peak, the displacement of sensor $A_{3}$ is mainly oriented along the $y$ axis, while it also occurs along the $z$ axis for sensor $A_{4}$ located $1 \mathrm{~m}$ above, revealing a significant upward displacement of the latter. In the distant plane, the displacement mainly occurs along the $x$ axis. More or less all sensors underwent a residual downward movement, revealing a small post-impact structure settlement.

The residual displacements along the $y$ axis are negative for sensors $A_{4}, A_{7}$ and $A_{8}$, suggesting that the structure moves globally opposite to the impact direction. This displacement is more pronounced close to the crest (e.g. $A_{4}$ vs. $A_{2}$ ). The same trend was observed within the levee above a height of $3 \mathrm{~m}$ from the ground (Fig. 11).

Similarly to what is observed for sensors $A_{7}$ and $A_{8}$ in the distant plane at the kernel-levee interface, sensors placed in the middle of the kernel in this same plane exhibit a significant residual displacement along the $x$ axis (Fig. 12). Considering the position of these sensors with respect to the impact 


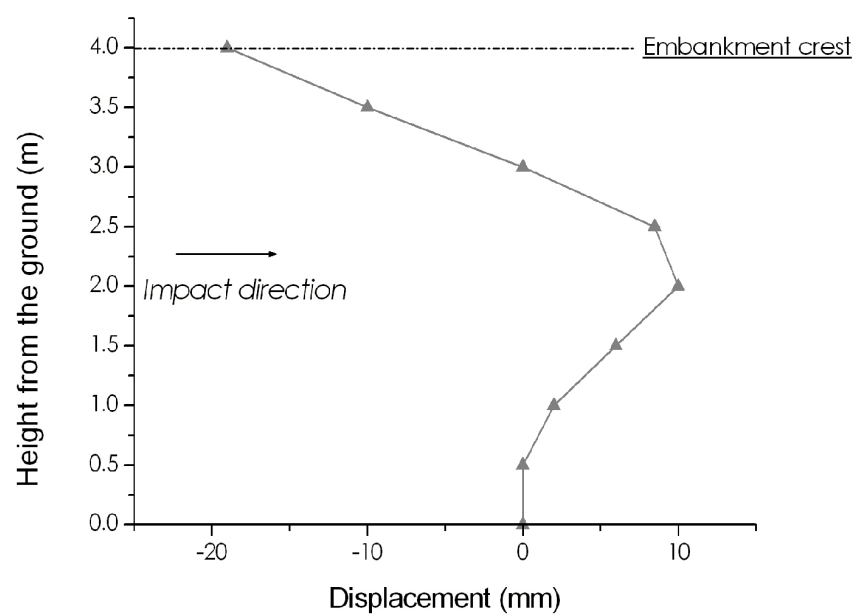

Figure 11. Displacements measured with the inclinometer within the levee, $0.50 \mathrm{~m}$ from the kernel-levee interface.

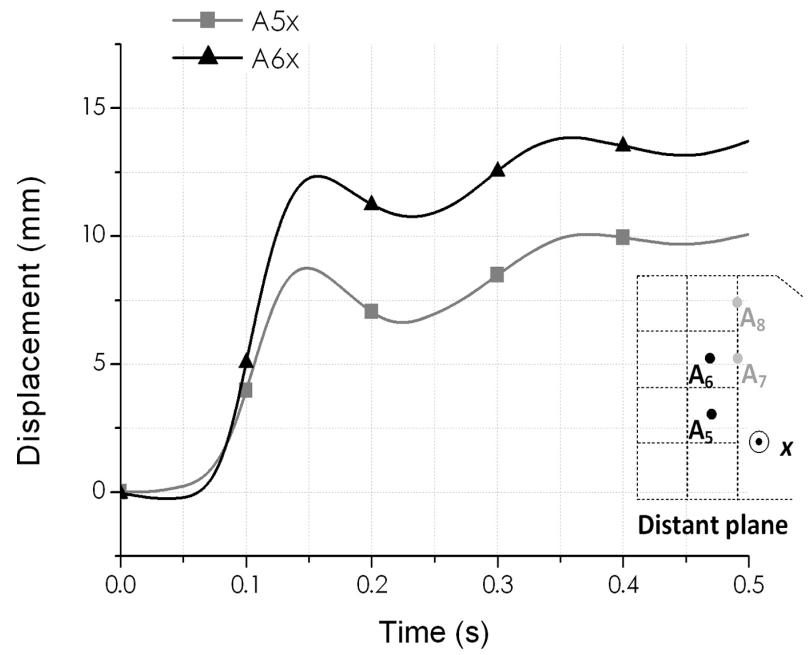

Figure 12. Displacements in the middle of the kernel, in the distant plane, along the $x$ axis.

point, this displacement is believed to result partly from the lateral expansion of the kernel in the impact axis direction, which undergoes compression along the $y$ axis. The residual displacement along the $x$ axis of $A_{7}$ is smaller than that of $A_{6}$, both positioned $3.5 \mathrm{~m}$ from the ground $(3 \mathrm{~mm} / 14 \mathrm{~mm})$. This is attributed to the geocell wire netting along the kernellevee interface that counters the displacement after the load peak (sensor $A_{7}$ ).

Based on these measurements, a schematic analysis of displacements observed at the impact height ( $2 \mathrm{~m}$ above ground) over time can be proposed (Fig. 13). The second stage typically corresponds to the maximum projectile penetration. Each geocell deforms along the two directions, with compression in the impact direction ( $y$ axis) and dilation in the tangential direction ( $x$ axis). The latter mechanism is partly countered by the internal connecting wires and by the wire
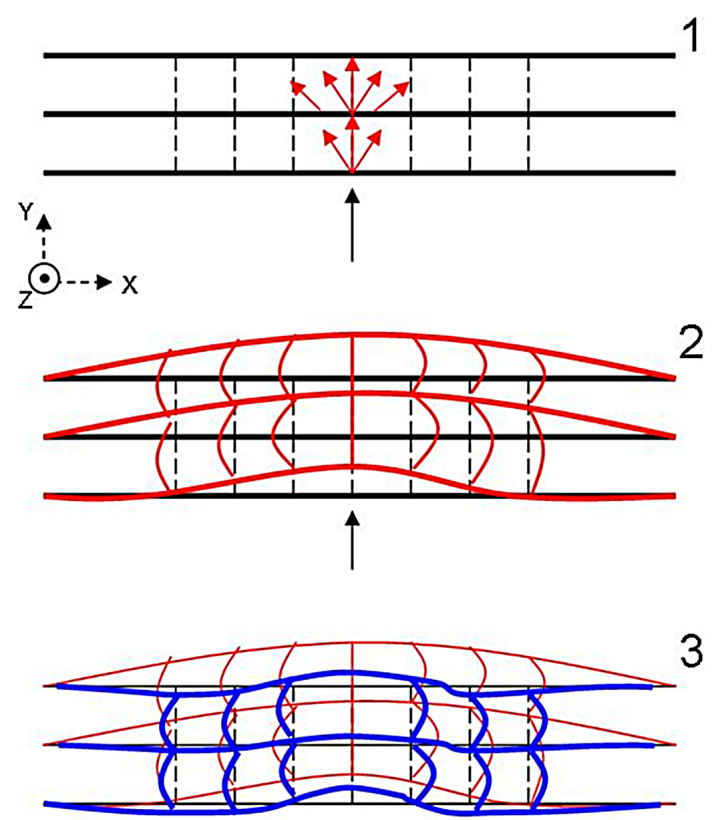

Figure 13. Schematic representation of the deformation of the sandwich wall at the impact height ( $2 \mathrm{~m}$ above the ground): (1) beginning of impact, (2) maximum deformation stage, (3) residual deformation.

netting at the vertical interfaces between the different layers. The deformation of the front facing does not concern the only impacted area. On the contrary, geocells around this area seem to be driven in the impact direction. This effect is attributed to the wire netting on the front facing that distributes the load to soil masses at a distance on both sides of the impacted area. As a consequence, the mass involved in the structure's response is increased and the stress diffusion angle is also expected to be higher. Both these mechanisms have a beneficial effect on the structure's ability to withstand the impact. The third stage corresponds to the global structure reverse displacement. This mechanism is mainly attributed to the elasticity of the sand-tyre mixture (Lambert et al., 2009).

\subsection{High-energy impact responses}

The damage to the structure as well as the penetration increased with increasing projectile kinetic energy. As the structure arrested the projectile without collapsing, it can be considered that the maximum impact energy used in the tests remains below the nominal capacity of the structure (Fig. 14).

After the fourth test, the structure exhibited different deformation patterns depending on the plane: compression in the impact plane and bending in the distant plane (Fig. 15). Cracks parallel to the kernel-levee interface were observed on the embankment crest between the kernel and the levee as well as about $1 \mathrm{~m}$ from this interface. Levee soil density 


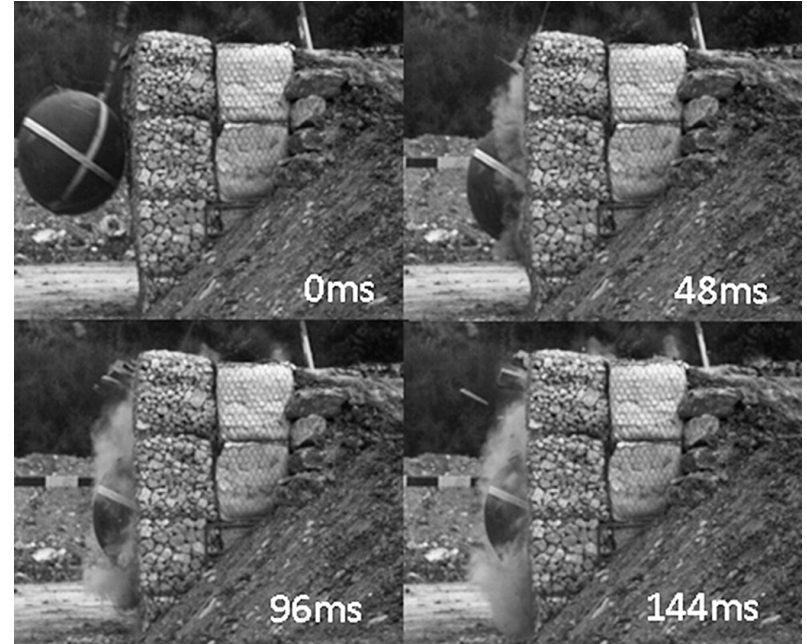

Figure 14. High-speed camera images during the fourth-impact test $(2200 \mathrm{~kJ})$.

changes were observed: bulking close to the kernel-levee interface as well as at a distance typically $2 \mathrm{~m}$ from this interface and compaction about $0.9 \mathrm{~m}$ from the interface, at a depth of 1-2 $\mathrm{m}$ from the crest.

The structure's response is first addressed in detail based on the displacements at the kernel-levee interface, which is an indirect but convenient estimator of the cellular wall efficiency in reducing the stress on the levee.

The incremental displacement of sensors in the impact plane during impact tests 1,3 and 4 is depicted in Fig. 16. The displacements strongly depend on the point considered and on the impact test. In the case of sensor 3, the deformation localisation observed after test 1 vanished for the other tests. For sensors 2 and 4, respectively above and below the impact height, a clear increase trend from the first to the last test was observed for both the maximum and residual displacement values. This trend mainly results from the displacement along the $y$ axis, this value predominating over the two other components. By contrast, the upward displacement increased during the test series and depends on the position of the sensor. At maximum, sensor $A_{4}$ moved by 160 and $80 \mathrm{~mm}$ along the $y$ axis and $z$ axis, respectively, during the last test.

The results reveal globally a change in the structure's response: while the first impact shows strain concentration, the two other impacts reveal a tilting movement on the whole structure, with higher amplitude close to the crest.

The interface displacements, i.e. the displacements along the $y$ axis, were much smaller than the projectile penetration (Table 2). Maximum penetrations as large as $1 \mathrm{~m}$ were measured during tests 2 and 4 . The residual penetration was typically $70 \%$ of the maximum penetration. By contrast, displacements measured at the kernel-levee interface were much lower, with residual values typically $10 \%$ of the projectile residual penetration. The maximum reverse displace-

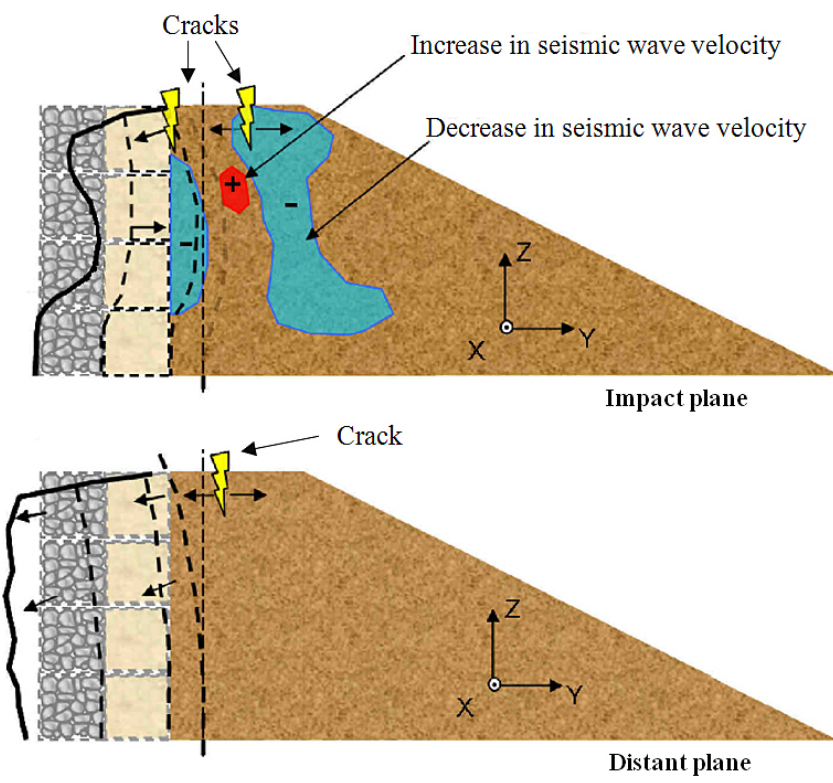

Figure 15. After the fourth impact, the sandwich wall exhibited a different deformation pattern from one plane to the other. Cracks, compaction and bulking were observed in the levee.

Table 2. Sandwich structure deformation at the impact height (na: not available).

\begin{tabular}{lccccc}
\hline $\begin{array}{l}\text { Test } \\
\#\end{array}$ & $\begin{array}{c}\text { Kinetic } \\
\text { energy } \\
(\mathrm{kJ})\end{array}$ & $\begin{array}{c}\text { Maximum } \\
(\mathrm{mm})\end{array}$ & $\begin{array}{c}\text { Residual } \\
(\mathrm{mm})\end{array}$ & $\begin{array}{c}\text { Maximum } \\
(\mathrm{mm})\end{array}$ & $\begin{array}{c}\text { Residual } \\
\text { displacement }\end{array}$ \\
\hline 1 & 210 & 500 & 335 & 104 & 52 \\
2 & 1040 & 980 & 730 & na & na \\
3 & 540 & 670 & 420 & 73 & 10 \\
4 & 2200 & 1010 & 710 & 124 & 55 \\
\hline
\end{tabular}

ment of the kernel-levee interface, i.e. in the direction opposite to the impact direction, was $70 \mathrm{~mm}$ (test 4). This may result from the kernel layer elasticity rather than from real soil levee displacement. The sensor was connected to the wire netting whose reverse displacement led to a void between the geocell and the levee (cracks, see Fig. 15).

\subsection{Comparison with other structure types}

A limited number of real-scale impact experiments have been conducted on comparatively different structures with respect to their cross-sectional shape, construction materials and size (Lambert and Bourrier, 2013). Testing conditions also varied from one study to another in terms of projectile mass and velocity. Despite this variability, these experiments globally provide a valuable database for comparison with the results presented in this paper. For this purpose, a representative panel of experiments from Hearn et al. (1996), Yoshida (1999), Peila et al. (2000, 2007), Sung et al. (2008) 
Table 3. Comparison with previous real-scale experiments with similar impact conditions (nm: not measurable).

\begin{tabular}{|c|c|c|c|c|}
\hline \multirow[t]{2}{*}{ Authors } & \multicolumn{2}{|c|}{ Embankment } & \multirow{2}{*}{$\begin{array}{c}\text { Projectile } \\
\text { kinetic } \\
\text { energy }(\mathrm{kJ})\end{array}$} & \multirow{2}{*}{$\begin{array}{l}\text { Penetration } \\
\quad(\mathrm{mm})\end{array}$} \\
\hline & $\begin{array}{l}\text { Height } \\
\text { (m) }\end{array}$ & $\begin{array}{c}\text { Width } \\
\text { (crest/base) }(\mathrm{m})\end{array}$ & & \\
\hline Aminata et al. (2008) & 2 & $1.5 / 2.25$ & 56 & 340 \\
\hline Yoshida (1999) & 4 & $4.3 / 5.3$ & 181 & 295 \\
\hline This study & 4 & $3.5 / 9$ & 210 & 335 \\
\hline Burroughs et al. (1993) & 3.1 & $1.8 / 1.8$ & 387 & 300 \\
\hline Maegawa et al. (2011) & 4.2 & $2.2 / 4.3$ & 697 & 824 \\
\hline This study & 4 & $4.5 / 9$ & 540 & 420 \\
\hline Burroughs et al. (1993) & 3.1 & $1.8 / 1.8$ & 1010 & 600 \\
\hline Maegawa et al. (2011) & 4.2 & $2.2 / 4.3$ & 1243 & 1560 \\
\hline This study & 4 & $4.5 / 9$ & 1040 & 730 \\
\hline Yoshida (1999) & 4 & $3.3 / 5.3$ & 2263 & n.m. \\
\hline Peila et al. $(2000,2007)$ & 4.2 & $0.9 / 5$ & 2500 & 600 \\
\hline Burroughs et al. (1993) & 3.1 & $1.8 / 1.8$ & 1400 & 900 \\
\hline Maegawa et al. (2011) & 4.2 & $2.2 / 4.3$ & 2037 & 1730 \\
\hline This study & 4 & $4.5 / 9$ & 2200 & 710 \\
\hline
\end{tabular}
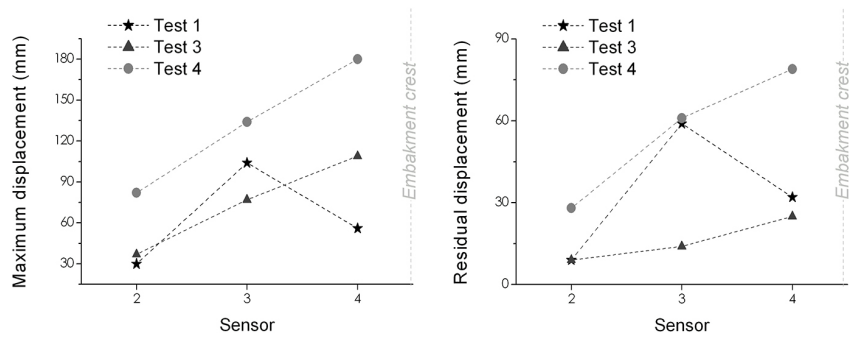

Figure 16. Maximum and residual incremental displacements at the kernel-levee interface in the impact plane after each impact (sensors $A_{2}, A_{3}$ and $\left.A_{4}\right)$.

and Maegawa et al. (2011) is considered. The considered experiments investigated an impact by a single projectile with a kinetic energy in the 50-2500 kJ range at approximately the structure's mid-height. The criterion for comparison is the residual projectile penetration, since it is the only data recorded in all cases (Table 3, Fig. 17).

For the lowest impact energies, the deformation of the front facing is similar for all cases (typically $300 \mathrm{~mm}$ for $200 \mathrm{~kJ}$ ). Differences appear when increasing the projectile's kinetic energy. For impact energies around $1000 \mathrm{~kJ}$, the maximum deformation measured on structures tested by Maegawa et al. (2011) was three times greater than that for cellular walls (our study). For impacts involving $2000 \mathrm{~kJ}$ kinetic energy projectiles, the latter type of structure performed similarly to structures tested by Peila et al. $(2000,2007)$ in terms of penetration.
Compared to the other structures, the width of the cellular embankment tested was significantly greater with a possible positive influence on its ability to withstand the impact. The fact that the projectile was stopped before the kernel-levee interface started moving significantly indicates that only a limited volume of the levee was involved before the projectile was stopped. As a consequence, it may be suggested that the size of the levee could have been significantly reduced, with only minor consequences for the embankment's ability to stop the projectile.

\section{Discussion}

On the whole, these results highlight several general trends regarding the response to localised impact of an embankment and its interaction with the projectile.

During the impact, the kinetic energy of the projectile is transferred to the embankment via the compression wave. It has been shown that the compression wave progressively travels from the impact point to the entire structure, within a cone. Its amplitude decreases due to both geometrical and material attenuations (Semblat and Luong, 1999; Ronco et al., 2009). The wave field can be considered spherical and the propagation direction radial from the impact point if the medium is isotropic and large enough. This compression wave results in a local increase in strain energy in the granular media, leading to plastic strain when in excess with respect to the mechanical characteristics of the material crossed. For instance, crushing of stones contained in the facing geocells and compaction in the levee have been 
- Maegawa et al., 2011

- Burroughs et al., 1993

- Aminata et al., 2008

Peila et al., 2000, 2007

$\nabla$ Yoshida, 1999

- This study

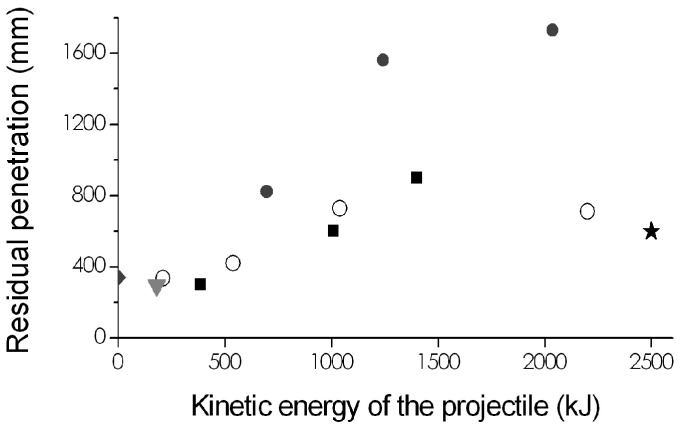

Figure 17. Penetration measured after impact on different real-scale structures.

shown in this study. Moreover, the rather large deformations of kernel geocells also confirm plastic strain in this layer. The compression wave also progressively leads to an increase in kinetic energy. Indeed, each elementary volume crossed by the compression wave is exposed to an unbalanced force and tends to be shifted in the wave propagation direction. Its displacement is countered by the neighbouring elementary volume in the wave propagation direction, which acts as a buttress (Lambert and Bourrier, 2013). This buttress effect depends on the neighbouring volume unit mass, mechanical characteristics and average stress. This explains why the upward movement at the kernel-levee interface displacements is higher above the projectile penetration axis, i.e. close to the crest. This phenomenon has been mentioned previously (Peila et al., 2007; Soudé et al., 2013; Hofmann et al., 2013). It results from the fact that the crest is a free boundary and that the weight of material above decreases, both resulting in a decrease in the buttress effect. The same mechanism explains the difference in soil levee characteristic changes observed from one point to another. Both the crack observed on the crest, $2 \mathrm{~m}$ from the kernel-levee interface and the decrease in seismic velocity observed more or less at the same distance within the levee core occurred due to an insufficient buttress effect. More precisely, when approaching the facing opposite the impacted facing, the compression wave resulted in increasing soil displacement. By contrast, at a distance of $1.5 \mathrm{~m}$ from the kernel-levee interface in the levee core, the compression wave increased soil compaction because the buttress effect was sufficient to counter the soil displacement.

During the first test, with a $210 \mathrm{~kJ}$ impact, the projectile was stopped in less than $200 \mathrm{~ms}$ and the maximum impact force was reached at $20 \mathrm{~ms}$. The projectile kinetic energy loss was rapid: 50 and $90 \%$ in 35 and $95 \mathrm{~ms}$, respectively. This contrasts with the characteristic time related to the structure's response. For example, the kernel-levee interface significantly moved starting at $50 \mathrm{~ms}$ and reached its maximum displacement at about $190 \mathrm{~ms}$. This shows that the interaction between the projectile and the embankment mainly involves a fraction of the structure, typically limited to $2 \mathrm{~m}$ away from the impact point. Likewise, the maximum impact force that is often used for the design of embankments is related to an even more limited fraction of the structure, as it is reached at the very beginning of the impact. This impact force may not be relevant for evaluating the load transmitted and thus displacement far away from the impact point.

These results suggest that the mechanical characteristics of the materials near the front facing govern the projectilestructure interaction and consequently the impact force, with consequences for the stress transmitted within the structure, while the characteristics of the whole structure govern its response and ability to survive the impact load. More generally, the description of the structure's response given in this study suggests that relevant design methods should be able to account for both the projectile-structure-facing interaction, on one side, and on the so-called buttress effect of the rest of the structure.

One of the key issues in assessing the response of rockfall protection embankments to impact is energy dissipation. Dissipation may result from three main mechanisms generating plastic strain: compaction, friction and crushing. The contribution over time of each of these mechanisms depends on the mechanical characteristics of the fill materials, on the distance to the impact point and on the impact energy (Lambert and Bourrier, 2013). According to numerical simulation results, compaction has been shown to predominate in embankments made up of fine granular materials for high-energy impacts (Ronco et al., 2009). However, measuring the different energy dissipation terms over time is not possible through experiments, and, in this specific case, estimating the dissipation by computing the kinetic and strain energy is tricky. The velocity field over the whole structure is too complex to estimate the kinetic energy precisely and it is difficult to compute strain energy in coarse materials as well as in the sand-tyre mixture undergoing significant strain and displacements. Finally, the propagation of the compression wave in the structure is not as simple as in infinite and isotropic media. Although not shown by the measurements, it can be stated that mechanisms such as scattering and reflection occur, with significant influence on the wave field and consequently on the displacement field. Leaving aside the question of tracking energy in the structure, the discussion mainly focuses on the advantages of sandwich structures based on the interpretation of the measurements.

The choice of different fill materials for the facing and kernel geocells aims at improving the efficiency of the wall by reducing the stress transmitted to the levee. Two ideas support this concept. First, deformation within the structure induces an increase in impact duration, resulting in a decrease in the stress transmitted. Indeed, it was shown that the stress transmitted by a two-layer wall was significantly reduced when decreasing the modulus of the kernel material (Bourrier et al., 2011). Second, deformation should preferably result 
from irreversible mechanisms leading to energy dissipation. As shown in a previous experimental study (Lambert et al., 2009), crushing is a fundamental phenomenon in the impact response of geocells filled with stones. First, crushing dissipates energy and, second, it limits the stress to a threshold, which depends on the size and crushing resistance of the stones. This limitation results in greater penetration of the projectile and a longer-lasting impact. In addition, at the structure scale, crushing leads to the quasi-plateau observed on the contact surface stress curve (Fig. 8). The same study shows that geocells filled with a sand-tyre mixture exhibit a smaller modulus and a smaller residual penetration and that the energy restitution to the projectile was higher than with geocells filled with stones. This difference stems from the progressive compaction of this finer fill material with increasing geocell deformation, its elastic properties and its interaction with the geocell envelope (Lambert et al., 2011). This is consistent with observations at the structure scale where high elastic recovery of the kernel was observed.

The difference in the compression response of the two layers, in terms of thickness reduction, thus results directly from the characteristics of the fill material.

\section{Conclusions}

In order to assess the response of cellular multi-layer protection embankments to rockfall impacts, real-scale impact experiments were conducted using a projectile with translational kinetic energies up to $2200 \mathrm{~kJ}$. The structure was made up of a two-layer sandwich wall consisting of gabion cages filled with either stones or a sand-shredded-tyre mixture leaned against a compacted soil levee. For the first time, the impacted structure was instrumented with accelerometers, displacement sensors and inclinometers.

The experiments provided highly valuable real-time data for quantifying the deformation and dynamic response of these structures. Comparison of the data from different sensor types was necessary for validation purposes. Nevertheless, this measuring context appeared highly detrimental to sensors, in particular due to the repetition of impacts.

Crushing of the coarse materials comprising the frontfacing layer dissipates energy and attenuates the stress on the second layer. The sand-tyre mixture exhibits elasticity that allows the second layer of the sandwich to restore its dimensions after impact. The wire netting distributes the load within the structure, while facilitating the structure postimpact repair.

The experiments prove the structure to be efficient for impact energies of at least $2200 \mathrm{~kJ}$. The levee dimensions may be reduced without altering this capacity. Moreover, the sandwich technology may be an efficient way of improving the efficiency of existing embankments. A sandwich wall leaned against an existing embankment will increase its ability to withstand high-energy impacts.
Finally, the set of collected data is of great interest for calibrating and validating numerical tools, and in particular the models based on DEM, FEM and DEM/FEM coupling whose development has been initiated within this research project (Nicot et al., 2007; Breugnot et al., 2010).

Acknowledgements. This research was funded by the French National Research Agency (ANR) within the REMPARe project. The authors wish to acknowledge all the partners of the project, especially Razel SA.

Edited by: P. Bartelt

Reviewed by: W. Gerber and T. Badger

\section{References}

Aminata, D., Yashima, A., Sawada, K., and Sung, E.: New protection wall against rockfall using a ductile cast iron panel, J. Nat. Dis. Sci., 30, 25-33, 2008.

Bertrand, D., Nicot, F., Gotteland, P., and Lambert, S.: Modelling a geo-composite geocell using discrete analysis, Comput and Geotech, 32, 564-577, 2005.

Blovsky, S.: Model tests on protective barriers against rockfall, in Proceedings of the 15th European Young Geotechnical Engineers Conference, Dublin, Ireland, 11-14 September 2002.

Bourrier, F., Lambert, S., Heymann, A., Gotteland, P., and Nicot, F.: How multi-scale approaches can benefit cellular structure design, Can. Geotech. J., 48, 1803-1816, 2011.

Breugnot, A., Gotteland, P., and Villard, P.: Numerical modelling of impacts on granular materials with a combined discretecontinuum approach, in: Proceedings of the 7th European conference on Numerical Methods in Geotechnical Engineering Trondheim, Norway, 2-4 June 2010, 477-482, 2010.

Burroughs, D. K., Henson, H. H., and Jiang, S. S.: Full scale geotextile rock barrier wall testing, analysis and prediction, in: Proceedings of Geosynthetics '93, Vancouver, Canada, 30 March1 April 1993, 959-970, 1993.

Dimnet, E., Haza-Rozier, E., Vinceslas, G., Leon, R., and Hernandez, G.: Experimental and numerical study of a shock-absorbing structure, Acta Mech., 224, 3037-3055, 2013.

Gotteland, P., Lambert, S., and Salot, C.: Investigating the strength characteristics of tyre chips - Sand mixtures for geo-cellular structure engineering, in: Proceedings of the International Workshop on Scrap Tire Derived Geomaterials - Opportunities and Challenges, Yokosuka, Japan, 23-24 March 2007, 351-361, 2008.

Haza-Rozier, E., Reiffsteck, P., Vinceslas, G., Lambert, S., Heymann, A., Gotteland, P., and Douaillat, M.: Tests on shockabsorber structures on a swinging impact site, in: Proceedings of Journées nationales de géotechnique et de géologie de l'ingénieur, Grenoble, France, 7-9 July 2010, 657-664, 2010.

Hearn, G., Barrett, R. K., and Henson, H. H.: Development of effective rockfall barriers, J. Transport. Engin., 121, 507-516, 1995.

Hearn, G., Barrett, R. K., and Henson, H. H.: Testing and modelling of two rockfall barriers, Transport. Res. Rec., 1504, 1-11, 1996.

Hennebert, P., Lambert, S., Fouillen, F., and Charrasse, B.: Assessing the environmental impact of shredded tires as embankment 
fill material, Can. Geotech. J., 51, 469-478, doi:10.1139/cgj2013-0194, 2014.

Heymann, A., Lambert, S., Haza-Rozier, E., Vinceslas, G., and Gotteland, P.: An experimental comparison of real-scale rockfall protection sandwich structures, in: Proceedings of the 11th conference on Structures under shock and impact, Tallinn, Estonia, 28-30 July 2010, 15-26, 2010.

Hofmann, R., Vollmert L., and Mölk, M.: Rockfall-protection embankments - design concept and construction details, in: proceedings of 18th International conference on soil mechanics and geotechnical engineering, Paris, France, 2-6 September 2013, 3107-3110, 2013.

Lambert, S. and Bourrier, F.: Design of rockfall protection embankments: a review, Eng. Geol., 154, 77-88, 2013.

Lambert, S., Gotteland, P., and Nicot, F.: Experimental study of the impact response of geocells as components of rockfall protection embankments, Nat. Hazards Earth Syst. Sci., 9, 459-467, doi:10.5194/nhess-9-459-2009, 2009.

Lambert, S., Nicot, F., and Gotteland, P.: Uniaxial compressive behavior of scrapped-tire and sand-filled wire netted geocell with a geotextile envelope, Geotext Geomembranes, 29, 483-490, 2011.

Lambert, S., Bourrier, F., and Toe, D.: Improving three-dimensional rockfall trajectory simulation codes for assessing the efficiency of protective embankments, Int. J. Rock Mech. Min., 60, 26-36, 2013.

Lee, H. J. and Roh, H. S.: The use of recycled tire chips to minimize dynamic earth pressure during compaction of backfill, Constr. Build Mater., 21, 1016-1026, 2007.

Maegawa, K., Tajima, T., Yokota, T., and Tohda, M.: Experiments on Rockfall Protection Embankments with Geogrids and Cushions, Int. J. Geomate, 1, 19-24, 2011.

Nicot, F., Gotteland, P., Bertrand, D., and Lambert, S.: Multi-scale approach to geo-composite cellular structures subjected to impact, Int. J. Numer. Anal. Meth. Geomech., 31, 1477-1515, 2007.
Peila, D.: Ground reinforced embankments for rockfall protection: From real scale tests to numerical modelling, in: Rockfall engineering, edited by: Lambert, S. and Nicot, F., John Wiley \& Sons, ISTE Ltd, New York, London, 393-426, 2011.

Peila, D., Castiglia, C., Oggeri, C., Guasti, G., Recalcati, P., and Sassudelli, F.: Full scale tests on geogrid reinforced embankments for rock fall protection, in: Proceedings of the 2nd European Geosynthetics Conference and Exhibition, Bologna, Italy, 15-18 October 2000, 317-322, 2000.

Peila, D., Oggeri, C., and Castiglia, C.: Ground reinforced embankments for rockfall protection: design and evaluation of full scale tests, Landslides, 4, 255-265, 2007.

Pichler, B., Hellmich, C., and Mang, H. A.: Impact of rocks onto gravel - Design and evaluation experiments, Int. J. Impact Engin., 31, 559-578, 2005.

Ronco, C., Oggeri, C., and Peila, D.: Design of reinforced ground embankments used for rockfall protection, Nat. Hazards Earth Syst. Sci., 9, 1189-1199, doi:10.5194/nhess-9-1189-2009, 2009.

Semblat, J.-F. and Luong, M. P.: Wave propagation through soils in centrifuge testing, J. Earth Q. Eng., 2, 147-171, 1998.

Soudé, M., Chevalier, B., Grédiac, M., Talon, A., and Gourvès, R.: Experimental and numerical investigation of the response of geocell-reinforced walls to horizontal localized impact, Geotext Geomembranes, 39, 39-50, 2013.

Sung, E., Yashima, A., Aminata, D., Sugimori, K., Sawada, K., Inoue, S., and Nishida, Y.: Numerical assessment of performance of protecting wall against rockfall, in: Proceedings of the 5th International Symposium on Earth Reinforcement, Fukuoka, Japan, 14-16 November 2007, 861-867, 2008.

Yoshida, H.: Recent experimental studies on rockfall control in Japan, in: Proceedings of the Joint Japan-Swiss scientific seminar on impact by rock falls and design of protection structures, Kanazawa, Japan, 4-7 October 1999, 69-78, 1999.

Zornberg, J. G., Cabral, A. R., and Viratjandr, C.: Behaviour of tire shred-sand mixtures, Can. Geotech. J., 41, 227-241, 2004. 